\title{
Recent technological progress in Asia from the First Asian Symposium on Laser-induced Breakdown Spectroscopy
}

\author{
Lian-Bo Guo (郭连波 $)^{1}$, Xiang-You Li (李祥友 $)^{1}$, Wei Xiong (熊伟 $)^{1}$, \\ Xiao-Yan Zeng (曾晓雁 $)^{1, \dagger}$, Yong-Feng Lu (陆永枫) $)^{1,2}$ \\ ${ }^{1}$ Wuhan National Laboratory for Optoelectronics, Huazhong University of Science and Technology (HUST), \\ 1037 Luoyu Road, Wuhan 430074, China \\ ${ }^{2}$ Department of Electrical Engineering, University of Nebraska-Lincoln, Lincoln, NE 68588-0511, USA

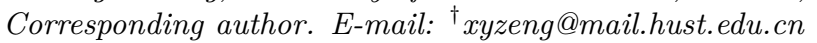 \\ Received October 6, 2016; accepted October 15, 2016
}

As an atomic emission spectroscopy technique, laserinduced breakdown spectroscopy (LIBS), first proposed by Breech and Cross in 1962 [1], has attracted much academic and industrial interest for its unique properties. By focusing a pulsed laser onto the surface of a target, laser-induced plasmas can be generated. The simplicity of sample preparation of the laser ablation process enables LIBS to directly analyze solid, liquid, or gaseous materials in the atmosphere, making it a convenient tool for chemical analyses. The unique features of LIBS such as requiring little or no sample preparation, allowing remote detection, and facilitating multiple elemental analyses have contributed to its rapid development in recent years.

Since LIBS was proposed in 1962, related research has quickly spread; however, the challenges of poor stability, reliability, and reproducibility remain. Since the 1990s, coinciding with significant improvement in performance of hardware such as the lasers, spectrometers, and detectors, LIBS research has reached prominence with various applications in different fields such as industrial production [2] and environmental monitoring [3]. To further develop LIBS and make it a more practical tool in chemical analyses, the first international LIBS conference, held in 2000 in Pisa, Italy, facilitated the formation of the international LIBS community. Since then, LIBS has entered an era of fast and comprehensive development.

Currently, three major LIBS communities, specifically, a Euro-Mediterranean Society (EMSLIBS), a North America Society (NASLIBS), and an Asian Society (ASLIBS), are jointly promoting LIBS science and

\footnotetext{
*Special Topic: The 1st Asian Symposium on Laser-induced Breakdown Spectroscopy (Eds. Xiao-Yan Zeng, Zhe Wang \& Yoshihiro Deguchi)
}

technology. LIBS has been regarded as a "future superstar" for chemical analyses [4]. The present trend suggests large-scale commercialization of LIBS and the change from a "future superstar" to an "actual superstar".

Among the three major LIBS societies, ASLIBS has experienced the fastest growth although it is a later comer. In 2011, the first Chinese Symposium on LIBS (CSLIBS) was successfully held in Qingdao, hosted by the Ocean University of China, which laid the foundation for the formation of a Chinese LIBS community. The first special issue on CSLIBS was published in the journal "Frontiers of Physics" in $2012[5,6]$. CSLIBS has rapidly developed since then, and has become the foundation of further LIBS development in Asia. One milestone is that the $8^{\text {th }}$ International Conference on LIBS (LIBS2014) was successfully held at Tsinghua University in September, 2014, which made ASLIBS as one of the three major LIBS communities in the world [7-9]. The success of LIBS2014 was followed by the first Asian Symposium on LIBS (ASLIBS2015) in Wuhan, hosted by the Wuhan National Laboratory for Optoelectronics and Huazhong University of Science and Technology. The number of attendees at ASLIBS2015 was greater than 200 from 8 countries (who gave 37 oral presentations and displayed 40 posters). ASLIBS2015 focused on the growth and application of new LIBS principles and methods, including novel industrial applications. To promote the development of LIBS, many aspects of LIBS research were included in ASLIBS2015, such as analysis of liquids [10-15], nuclear industry applications [16-21], in-situ and on-line analysis of steel [21-25], analysis of soils and agricultural applications [26-29], coal analysis [30-34], and spectral data processing [35-41]. The first special issue regarding the Chinese LIBS community was published on 
the journal "Frontiers of Physics" in 2012 [5]; the second special issue was published in the journal "Plasma Science and Technology" after LIBS2014 [42]. The current special issue regarding ASLIBS2015, is the third special issue from Chinese LIBS community; it includes articles reviewing the progress of LIBS in Asia [43], coal analysis [44], fusion applications [45], and other applications [46-48].

As seen from ASLIBS2015, as a chemical analysis technique, LIBS is in a period of vigorous development in Asia. Although many challenges remain, significant achievements fundamentals, instrumentation, and applications have been made. (i) Regarding the fundamentals of LIBS, the sensitivity enhancement of LIBS has focused on signal enhancement with magnetic confinement [49-51], spatial confinement [52-55], fast pulse discharge [56, 57], and dual-pulse lasers [58-60]. Laserinduced fluorescence (LIF) in plasmas is another method used to realize highly selective enhancement in LIBS, namely LIBS-LIF [61]. (ii) Regarding instrumentation, more than eight groups in China are committed to manufacturing instruments for industrial production. Two research groups from the Huazhong University of Science and Technology and Sichuan University have developed desktop and portable LIBS systems [62, 63]. (iii) Regarding LIBS applications, the steel industry has been an important area. At present, several groups, including those at the Huazhong University of Science and Technology, Shenyang Institute of Automation, and the Chinese Academy of Sciences, are working in this area [64-67], with research topics gradually changing from basic research to in-situ and on-line detection. LIBS appears to be a very promising analysis method in mineral processing and metallurgy processes. Coal analysis is another field in which LIBS has great potential. Four groups, including the South China University of Technology [6873], Tsinghua University [17], Shanxi University [72-75], and University of Tokushima [76, 77], have been concentrating on improving the analysis accuracy for different components of coal that affect coal quality. For applications in soil analysis, sample preparation proved useful for soil classification [78]. Novel methods [79-82], such as standard addition methods combined with wavelet transforms, and laser ablation assisted with spark have been used to improve the accuracy of soil analysis, and the application studies show that LIBS seems to be a potential technique [83-85]. In liquid analyses, the Ocean University of China first realized LIBS for underwater detection $[86,87]$. Meanwhile, groups in Japan utilized electrodeposition with underwater LIBS for analyses of trace metals in aqueous solutions. Many novel methods have been introduced to detect liquid samples, including surfaceenhanced LIBS [88], changing liquid samples from static to dynamic [89], absorbing samples using solids [91], and drying on metallic surfaces [92]. Data processing can be used to compensate for the shortcomings of hardware.

To improve the quality and quantity of LIBS information, data preprocessing methods were rapidly developed in recent years. Denoising [83-97], spectrum standardization [98, 99], continuous background removal [100], overlapping peak resolution [101], self-absorption correction [102, 103], data analysis methods including partial least squares (PLS) [104], the support vector machine [105], and random forest regression [106] model have received thorough study. Specifically, a novel method using the dominant-factor-based multivariate model has been proposed; it proved to be effective in terms of improving the accuracy and precision of LIBS [106].

In the future, LIBS, a promising technique with excellent features such as requiring little or no sample preparation, allowing remote detection, and facilitating multiple elemental analyses, will meet a large range of demands in various areas. However, poor stability, repeatability, and reproducibility remain important challenges. LIBS researchers are motivated to overcome these drawbacks to realize large-scale commercialization of LIBS.

\section{References}

1. F. Brech and L. Cross, Optical microemission stimulated by a ruby laser, Appl. Spectrosc. 16(2), 59 (1962)

2. C. Aragón, J. A. Aguilera, and J. Campos, Determination of carbon content in molten steel using laser-induced breakdown spectroscopy, Appl. Spectrosc. 47(5), 606 (1993)

3. A. Ciucci, V. Palleschi, S. Rastelli, R. Barbini, F. Colao, R. Fantoni, A. Palucci, S. Ribezzo, and H. J. L. van der Steen, Trace pollutants analysis in soil by a time-resolved laser-induced breakdown spectroscopy technique, Appl. Phys. B 63(2), 185 (1996)

4. J. D. Winefordner, I. B. Gornushkin, T. Correll, E. Gibb, B. W. Smith, and N. Omenetto, Comparing several atomic spectrometric methods to the super stars: Special emphasis on laser induced breakdown spectrometry, LIBS, a future super star, J. Anal. At. Spectrom. 19(9), 1061 (2004)

5. J. Yu and R. Zheng, Laser-induced plasma and laserinduced breakdown spectroscopy (LIBS) in China: The challenge and the opportunity, Front. Phys. 7(6), 647 (2012)

6. Z. B. Ni, X. L. Chen, H. B. Fu, J. G. Wang, and F. Z Dong, Study on quantitative analysis of slag based on spectral normalization of laser-induced plasma image, Front. Phys. 9(4), 439 (2014)

7. H. K. Sanghapi, K. K. Ayyalasomayajula, F. Y. Yueh, J. P. Singh, D. L. McIntyre, J. C. Jain, and J. Nakano, 
Analysis of slags using laser-induced breakdown spectroscopy, Spectrochim. Acta B At. Spectrosc. 115, 40 (2016)

8. Z. Z. Wang, J. J. Yan, J. P. Liu, Y. Deguchi, S. Katsumori, and A. Ikutomo, Sensitive cesium measurement in liquid sample using low-pressure laser-induced breakdown spectroscopy, Spectrochim. Acta B At. Spectrosc. 114, 74 (2015)

9. M. Martin, R. C. Martin, S. Allman, D. Brice, A. Wymore, and N. Andre, Quantification of rare earth elements using laser-induced breakdown spectroscopy, Spectrochim. Acta B At. Spectrosc. 114, 65 (2015)

10. T. Sakka, A. Tamura, A. Matsumoto, K. Fukami, N. Nishi, and B. Thornton, Effects of pulse width on nascent laser-induced bubbles for underwater laserinduced breakdown spectroscopy, Spectrochim. Acta B At. Spectrosc. 97, 94 (2014)

11. B. Thornton, T. Takahashi, T. Sato, T. Sakka, A. Tamura, A. Matsumoto, T. Nozaki, T. Ohki, and K. Ohki, Development of a deep-sea laser-induced breakdown spectrometer for in situ multi-element chemical analysis, Deep Sea Res. Part I Oceanogr. Res. Pap. 95, 20 (2015)

12. A. Tamura, A. Matsumoto, K. Fukami, N. Nishi, and T. Sakka, Simultaneous observation of nascent plasma and bubble induced by laser ablation in water with various pulse durations, J. Appl. Phys. 117(17), 173304 (2015)

13. Y. Tian, B. Y. Xue, J. J. Song, Y. Lu, and R. E. Zheng, Non-gated laser-induced breakdown spectroscopy in bulk water by position-selective detection, Appl. Phys. Lett. 107(111107), 1 (2016)

14. Y. Lu, Y. D. Li, Y. Li, Y. F. Wang, S. Wang, Z. M. Bao, and R. E. Zheng, Micro spatial analysis of seashell surface using laser-induced breakdown spectroscopy and Raman spectroscopy, Spectrochim. Acta B At. Spectrosc. 110, 63 (2015)

15. X. Y. Yang, Z. Q. Hao, C. M. Li, J. M. Li, R. X. Yi, M. Shen, K. H. Li, L. B. Guo, X. Y. Li, and Y. F. Lu, Sensitive determinations of $\mathrm{Cu}, \mathrm{Pb}, \mathrm{Cd}$, and $\mathrm{Cr}$ elements in aqueous solutions using chemical replacement combined with surface-enhanced laser-induced breakdown spectroscopy, Opt. Express 3, 24 (2016)

16. M. Tampo, M. Miyabe, K. Akaoka, M. Oba, H. Ohba, Y. Maruyama, and I. Wakaida, Enhancement of intensity in microwave-assisted laser-induced breakdown spectroscopy for remote analysis of nuclear fuel recycling, J. Anal. At. Spectrom. 29(5), 886 (2014)

17. M. Saeki, A. Iwanade, C. Ito, I. Wakaida, B. Thornton, T. Sakka, and H. Ohba, Development of a fibercoupled laser-induced breakdown spectroscopy instrument for analysis of underwater debris in a nuclear reactor core, J. Nucl. Sci. Technol. 51(7-8), 930 (2014)

18. D. Zhao, N. Farid, R. Hai, D. Wu, and H. Ding, Diagnostics of first wall materials in a magnetically confined fusion device by polarization-resolved laser-induced breakdown spectroscopy, Plasma Sci. Technol. 16(2), 149 (2014)
19. C. Li, X. Wu, C. Zhang, H. Ding, J. Hu, and G. N. Luo, H.B.ding, In situ chemical imaging of lithiated tungsten using laser-induced breakdown spectroscopy, J. Nucl. Mater. 452(1-3), 10 (2014)

20. R. Hai, N. Farid, D. Y. Zhao, L. Zhang, J. H. Liu, H. B. Ding, J. Wu, and G. N. Luo, Laser-induced breakdown spectroscopic characterization of impurity deposition on the first wall of a magnetic confined fusion device: Experimental advanced superconducting tokamak, Spectrochim. Acta B At. Spectrosc. 87, 147 (2013)

21. K. Akaoka, Y. Maruyama, M. Oba, M. Miyabe, I. Wakaida, Development of laser remote analysis for nuclear fuel materials 2:(2) Evaluation of Measurement Accuracy using Laser Induced Breakdown Spectroscopy for High Concentration Elements, Proceedings of AESJ 2013 (2013)

22. J. Gruber, J. Heitz, H. Strasser, D. Bauerle, and N. Ramaseder, Rapid in-situ analysis of liquid steel by laserinduced breakdown spectroscopy, Spectrochim. Acta B At. Spectrosc. 56(6), 685 (2001)

23. L. X. Sun, Y. Xin, Z. B. Cong, Y. Li, and L. F. Qi, Online compositional analysis of molten steel by laserinduced breakdown spectroscopy, Adv. Mat. Res. 694697, 1260 (2013)

24. H. Y. Kong, L. X. Sun, J. T. Hu, Y. Xin, and Z. B. Cong, Selection of spectral data for classification of steels using laser-induced breakdown spectroscopy, Plasma Sci. Technol. 17(11), 964 (2015)

25. Z. Q. Hao, C. M. Li, M. Shen, X. Y. Yang, K. H. Li, L. B. Guo, X. Y. Li, Y. F. Lu, and X. Y. Zeng, Acidity measurement of iron ore powders using laser-induced breakdown spectroscopy with partial least squares regression, Opt. Express 23(6), 7795 (2015)

26. K. Q. Yu, Y. R. Zhao, F. Liu, and Y. He, LaserInduced Breakdown Spectroscopy Coupled with Multivariate Chemometrics for Variety Discrimination of Soil, Sci. Rep. 6, 27574 (2016)

27. R. X. Yi, L. B. Guo, X. H. Zou, J. M. Li, Z. Q. Hao, X. Y. Yang, X. Y. Li, X. Y. Zeng, and Y. F. Lu, Background removal in soil analysis using laser-induced breakdown spectroscopy combined with standard addition method, Opt. Express 24(3), 2607 (2016)

28. Y. Z. Lin, M. Y. Yao, M. H. Liu, Q. M. Peng, X. Zhang, T. B. Chen, and Y. Xu, Determination of parameter range in detecting $\mathrm{Cu}$ of Gannan navel orange by LIBS setup, Spectroscopy and Spectral Analysis. 32(11), 2925 (2012)

29. P. C. Zheng, M. J. Shi, J. M. Wang, and H. D. Liu, The spectral emission characteristics of laser induced plasma on tea samples, Plasma Sci. Technol. 17(8), 664 (2015)

30. X. W. Li, X. L. Mao, Z. Wang, and R. E. Russo, Quantitative analysis of carbon content in bituminous coal by laser-induced breakdown spectroscopy Using UV laser radiation, Plasma Sci. Technol. 17(11), 928 (2015) 
31. S. C. Yao, J. L. Xu, K. J. Bai, and J. D. Lu, Improved Measurement Performance of Inorganic Elements in Coal by Laser-Induced Breakdown Spectroscopy Coupled with Internal Standardization, Plasma Sci. Technol. 17(11), 938 (2015)

32. Z. Wang, Y. Deguchi, H. Watanabe, R. Kurose, J. Yan, and J. Liu, Improvement on quantitative measurement of fly ash contents using laser-induced breakdown spectroscopy, Journal of Flow Control Measurement \& Visualization 03(01), 10 (2015)

33. Y. Deguchi, T. Kamimoto, Z. Z. Wang, J. J. Yan, J. P. Liu, H. Watanabe, and R. Kurose, Applications of laser diagnostics to thermal power plants and engines, Appl. Therm. Eng. 73(2), 1453 (2014)

34. Z. Z. Wang, Y. Deguchi, J. J. Yan, J. P. Liu, Rapid detection of mercury and iodine using laser breakdown time-of-flight mass spectrometry, Spectrosc. Lett. 48(2), $128(2015)$

35. X. H. Zou, L. B. Guo, M. Shen, X. Y. Li, Z. Q. Hao, Q. D. Zeng, Y. F. Lu, Z. M. Wang, and X. Y. Zeng, Accuracy improvement of quantitative analysis in laser induced breakdown spectroscopy using modified wavelet transform, Opt. Express 22(9), 10233 (2014)

36. X. W. Li, Z. Wang, Y. T. Fu, Z. Li, and W. D. Ni, Wavelength dependence in the analysis of carbon content in coal by nanosecond $266 \mathrm{~nm}$ and $1064 \mathrm{~nm}$ laser induced breakdown spectroscopy, Plasma Sci. Technol. $17(8), 621(2015)$

37. X. W. Li, W. Zhe, Z. Li, and W. D. Ni, A model combining spectrum standardization and dominant factor based partial least square method for carbon analysis in coal using laser-induced breakdown spectroscopy, Spectrochim. Acta. B 99, 82 (2014)

38. R. Wang, X. H. Ma, Q. Yu, Y. Song, H. F. Zhao, M. Zhang, and Y. B. Liao, Methods of Data Processing for Trace Elements Analysis Using Laser Induced Breakdown Spectroscopy, Plasma Sci. Technol. 17(11), 944 (2015)

39. A. Sarkar, V. Karki, S. K. Aggarwal, G. S. Maurya, R. Kumar, A. K. Rai, X. L. Mao, and R. E. Russo, Evaluation of the prediction precision capability of partial least squares regression approach for analysis of high alloy steel by laser induced breakdown spectroscopy, Spectrochim. Acta. B 108, 8 (2015)

40. J. H. Yang, C. C. Yi, J. W. Xu, and X. H. Ma, Laserinduced breakdown spectroscopy quantitative analysis method via adaptive analytical line selection and relevance vector machine regression model, Spectrochim. Acta B At. Spectrosc. 107, 45 (2015)

41. B. Zhang, L. X. Sun, H. B. Yu, Y. Xin, and Z. B. Cong, Wavelet denoising method for laser-induced breakdown spectroscopy, J. Anal. At. Spectrom. 28(12), 1884 (2013)

42. Z. Wang, F. Z. Dong, and W. D. Zhou, A rising force for the world-wide development of laser-induced breakdown spectroscopy, Plasma Sci. Technol. 17(8), 617 (2015)
43. Z. Z. Wang, Y. Deguchi, Z. Z. Zhang, Z. Wang, X. Y. Zeng, and J. J. Yan, Laser-induced breakdown spectroscopy in Asia, Front. Phys. 11(6), 114213 (2016)

44. Y. Zhao, L. Zhang, S. X. Zhao, Y. F. Li, Y. Gong, L. Dong, W. G. Ma, W. B. Yin, S. C. Yao, J. D. Lu, L. T. Xiao, and S. T. Jia, Review of methodological and experimental LIBS techniques for coal analysis and their application in power plants in China, Front. Phys. 11(6), 114211 (2016)

45. C. Li, C. L. Feng, H. Y. Oderji, G. N. Luo, and H. B. Ding, Review of LIBS application in nuclear fusion technology, Front. Phys. 11(6), 114214 (2016)

46. Y. Xin, L. X. Sun, Z. J. Yang, P. Zeng, Z. B. Cong, and L. F. Qi, In situ analysis of magnesium alloy using a standoff and double-pulse laser-induced breakdown spectroscopy system, Front. Phys. 11(5), 115207 (2016)

47. Y. M. Guo, L. B. Guo, J. M. Li, H. D. Liu, Z. H. Zhu, X. Y. Li, Y. F. Lu, and X. Y. Zeng, Research progress in Asia on methods of processing laser-induced breakdown spectroscopy data, Front. Phys. 11(5), 114212 (2016)

48. S. L. Zhong, Y. Lu, W. J. Kong, K. Cheng, and R. E. Zheng, Quantitative analysis of lead in aqueous solutions by ultrasonic nebulizer assisted laser induced breakdown spectroscopy, Front. Phys. 11(4), 114202 (2016)

49. V. N. Rai, A. K. Rai, F. Y. Yueh, and J. P. Singh, Optical emission from laser-induced breakdown plasma of solid and liquid samples in the presence of a magnetic field, Appl. Opt. 42(12), 2085 (2003)

50. Z. Q. Hao, L. B. Guo, C. M. Li, M. Shen, X. H. Zou, X. Y. Li, Y. F. Lu, and X. Y. Zeng, Sensitivity improvement in the detection of $\mathrm{V}$ and $\mathrm{Mn}$ elements in steel using laser-induced breakdown spectroscopy with ring-magnet confinement, J. Anal. At. Spectrom. 29(12), 2309 (2014)

51. L. B. Guo, W. Hu, B. Y. Zhang, X. N. He, C. M. Li, Y. S. Zhou, Z. X. Cai, X. Y. Zeng, and Y. F. Lu, Enhancement of optical emission from laser-induced plasmas bycombined spatial and magnetic confinement, Opt. Express 19(15), 14067 (2011)

52. X. K. Shen, J. Sun, H. Ling, and Y. F. Lu, Spectroscopic study of laser-induced Al plasmas with cylindrical confinement, J. Appl. Phys. 102(9), 093301 (2007)

53. D. H. Lee, S. C. Han, T. H. Kim, and J. I. Yun, Highly sensitive analysis of boron and lithium in aqueous solution using dual-pulse laser-induced breakdown spectroscopy, Anal. Chem. 83(24), 9456 (2011)

54. X. W. Li, Z. Wang, X. L. Mao, and R. Russo, Spatially and temporally resolved spectral emission of laserinduced plasmas confined by cylindrical cavities, $J$. Anal. At. Spectrom. 29(11), 2127 (2014)

55. Z. Y. Hou, Z. Wang, J. M. Liu, W. D. Ni, and Z. $\mathrm{Li}$, Combination of cylindrical confinement and spark discharge for signal improvement using laser induced breakdown spectroscopy, Opt. Express 22(11), 12909 (2014) 
56. W. D. Zhou, K. X. Li, Q. M. Shen, Q. L. Chen, and J. M. Long, Optical emission enhancement using laser ablation combined with fast pulse discharge, Opt. Express 18(3), 2573 (2010)

57. W. D. Zhou, K. X. Li, H. G. Qian, Z. J. Ren, and Y. $\mathrm{L}$. $\mathrm{Yu}$, Effect of voltage and capacitance in nanosecond pulse discharge enhanced laser-induced breakdown spectroscopy, Appl. Opt. 51(7), B42 (2012)

58. R. Ahmed, and M. A. Baig, A comparative study of single and double pulse laser induced breakdown spectroscopy, J. Appl. Phys. 106(3), 033307 (2009)

59. Z. Sukra Lie, M. On Tjia, R. Hedwig, M. Margaretha Suliyanti, S. Nur Abdulmadjid, N. Idris, A. Mangasi Marpaung, M. Pardede, E. Jobiliong, M. Ramli, H. Suyanto, K. Fukumoto, K. Kagawa, and K. Hendrik Kurniawan, Direct evidence of mismatching effect on $\mathrm{H}$ emission in laser-induced atmospheric helium gas plasma, J. Appl. Phys. 113(5), 053301 (2013)

60. R. Hai, X. Wu, Y. Xin, P. Liu, D. Wu, H. Ding, Y. Zhou, L. Cai, and L. Yan, Use of dual-pulse laser-induced breakdown spectroscopy for characterization of the laser cleaning of a first mirror exposed in HL-2A, J. Nucl. Mater. 447(1-3), 9 (2013)

61. J. M. Li, L. B. Guo, N. Zhao, X. Y. Yang, R. X. Yi, K. H. Li, Q. D. Zeng, X. Y. Li, X. Y. Zeng, and Y. Lu, Determination of cobalt in low-alloy steels using laserinduced breakdown spectroscopy combined with laserinduced fluorescence, Talanta 151, 234 (2016)

62. Q. D. Zeng, L. B. Guo, X. Y. Li, M. Shen, Y. N. Zhu, J. M. Li, X. Y. Yang, K. H. Li, J. Duan, X. Y. Zeng, and Y. F. Lu, Quantitative analyses of Mn, V, and Si elements in steels using a portable laser-induced breakdown spectroscopy system based on a fiber laser, J. Anal. At. Spectrom. 31(3), 767 (2016)

63. Q. Y. Lin, Z. M. Wei, M. Q. Xu, S. Wang, G. H. Niu, K. P. Liu, Y. X. Duan, and J. Yang, Laser-induced breakdown spectroscopy for solution sample analysis using porous electrospun ultrafine fibers as a solid-phase support, RSC Advances 4(28), 14392 (2014)

64. L. X. Sun, Y. Xin, Z. B. Cong, Y. Li, and L. F. Qi, Online compositional analysis of molten steel by laserinduced breakdown spectroscopy, Adv. Mat. Res. 694$697,1260(2013)$

65. B. Zhang, L. X. Sun, and H. B. Yu, An Improving Method for Background Correction in Laser Induced Breakdown Spectroscopy, Appl. Mech. Mater. 751, 86 (2015)

66. K. H. Li, L. B. Guo, C. M. Li, X. Y. Li, M. Shen, Z. Zheng, Y. Yu, R. F. Hao, Z. Q. Hao, Q. D. Zeng, Y. F. Lu, and X. Y. Zeng, Analytical-performance improvement of laser-induced breakdown spectroscopy for steel using multi-spectral-line calibration with an artificial neural network, J. Anal. At. Spectrom. 30(7), 1623 (2015)
67. T. Fei, Q. P. Wang, X. Y. Lu, S. B. Wang, and C. Y. Pan, Experimental analysis of carbon content in carbon steel by laser-induced plasma spectroscopy method, Chinese Journal of Quantum Electronics 29(2), 209 (2012)

68. M. R. Dong, J. D. Lu, S. C. Yao, J. Li, J. Y. Li, Z. M. Zhong, and W. Y. Lu, Application of LIBS for direct determination of volatile matter content in coal, J. Anal. At. Spectrom. 26(11), 2183 (2011)

69. S. C. Yao, J. D. Lu, J. P. Zheng, and M. R. Dong, Analyzing unburned carbon in fly ash using laser-induced breakdown spectroscopy with multivariate calibration method, J. Anal. At. Spectrom. 27(3), 473 (2012)

70. S. C. Yao, J. D. Lu, J. Y. Li, K. Chen, J. Li, and M. R. Dong, Multi-elemental analysis of fertilizer using laserinduced breakdown spectroscopy coupled with partial least squares regression, J. Anal. At. Spectrom. 25(11), 1733 (2010)

71. S. C. Yao, J. D. Lu, K. Chen, S. H. Pan, J. Y. Li, and M. R. Dong, Study of laser-induced breakdown spectroscopy to discriminate pearlitic/ferritic from martensitic phases, Appl. Surf. Sci. 257(7), 3103 (2011)

72. T. B. Yuan, Z. Wang, L. Z. Li, Z. Y. Hou, Z. Li, and W. D. Ni, Quantitative carbon measurement in anthracite using laser-induced breakdown spectroscopy with binder, Appl. Opt. 51(7), B22 (2012)

73. Z. Wang, T. B. Yuan, S. L. Lui, Z. Y. Hou, X. W. Li, Z. Li, and W. D. Ni, Major elements analysis in bituminous coals under different ambient gases by laserinduced breakdown spectroscopy with PLS modeling, Front. Phys. 7(6), 708 (2012)

74. Z. Y. Hou, Z. Wang, J. M. Liu, W. D. Ni, and Z. Li, Signal quality improvement using cylindrical confinement for laser induced breakdown spectroscopy, Opt. Express 21(13), 15974 (2013)

75. T. B. Yuan, Z. Wang, S. L. Lui, Y. T. Fu, Z. Li, J. M. Liu, and W. D. Ni, Coal property analysis using laserinduced breakdown spectroscopy, J. Anal. At. Spectrom. 28(7), 1045 (2013)

76. Z. Z. Wang, Y. Deguchi, M. Kuwahara, J. J. Yan, and J. P. Liu, Enhancement of laser-induced breakdown spectroscopy (LIBS) detection limit using a low-pressure and short-pulse laser-induced plasma process, Appl. Spectrosc. 67(11), 1242 (2013)

77. A. Khumaeni, Z. S. Lie, H. Niki, K. H. Kurniawan, E. Tjoeng, Y. I. Lee, K. Kurihara, Y. Deguchi, and K. Kagawa, Direct analysis of powder samples using transversely excited atmospheric $\mathrm{CO}_{2}$ laser-induced gas plasma at 1 atm, Anal. Bioanal. Chem. 400(10), 3279 (2011)

78. K.Q. Yu, Y.R. Zhao, F. Liu, and Y. He, Laserinduced breakdown spectroscopy coupled with multivariate chemometrics for variety discrimination of soil, Sci. Rep. 6, 27574 (2016) 
79. X. F. Li, W. D. Zhou, and Z. F. Cui, Temperature and electron density of soil plasma generated by LA-FPDPS, Front. Phys. 7(6), 721 (2012)

80. R. X. Yi, L. B. Guo, X. H. Zou, J. M. Li, Z. Q. Hao, X. Y. Yang, X. Y. Li, X. Y. Zeng, and Y. F. Lu, Background removal in soil analysis using laser- induced breakdown spectroscopy combined with standard addition method, Opt. Express 24(3), 2607 (2016)

81. K. X. Li, W. D. Zhou, Q. M. Shen, Z. J. Ren, and B. J. Peng, Laser ablation assisted spark induced breakdown spectroscopy on soil samples, J. Anal. At. Spectrom. 25(9), 1475 (2010)

82. T. B. Chen, M. Y. Yao, M. H. Liu, Z. J. Lei, Q. M. Peng, Y. Xu, and X. Zhang, Quantitative analysis of Ba and Sr in soil using laser-induced breakdown spectroscopy, Spectroscopy and Spectral Analysis 32(6), 1658 (2012)

83. P. Y. Meslin, O. Gasnault, O. Forni, S. Schröder, A. Cousin, et al., Soil diversity and hydration as observed by ChemCam at Gale crater, Mars, Science 341(6153), 1238670 (2013)

84. N. Idris, M. Ramli, R. Hedwig, Z.S. Lie, K.H. Kurniawan, Preliminary study on detection sediment contamination in soil affected by the Indian Ocean giant tsunami 2004 in Aceh, Indonesia using laser-induced breakdown spectroscopy (LIBS), 1719(030051), 1-4 (2016)

85. S. Pandhija and A. K. Rai, Screening of brick-kiln area soil for determination of heavy metal $\mathrm{Pb}$ using LIBS, Environ. Monit. Assess. 148(1-4), 437 (2009)

86. Y. Tian, B. Y. Xue, J. J. Song, Y. Lu, and R. E. Zheng, Non-gated laser-induced breakdown spectroscopy in bulk water by position-selective detection, Appl. Phys. Lett. 107(111107), 1 (2016)

87. Y. Lu, Y. D. Li, Y. Li, Y. F. Wang, S. Wang, Z. M. Bao, and R. E. Zheng, Micro spatial analysis of seashell surface using laser-induced breakdown spectroscopy and Raman spectroscopy, Spectrochim. Acta B At. Spectrosc. 110, 63 (2015)

88. M. A. Aguirre, S. Legnaioli, F. Almodóvar, M. Hidalgo, V. Palleschi, and A. Canals, Elemental analysis by surface-enhanced Laser-Induced Breakdown Spectroscopy combined with liquid-liquid microextraction, Spectrochim. Acta B At. Spectrosc. 79-80, 88 (2013)

89. L. Shi, Q. Y. Lin, and Y. X. Duan, A novel specimenpreparing method using epoxy resin as binding material for LIBS analysis of powder samples, Talanta 144, 1370 (2015)

90. Q. Y. Lin, X. D. Han, J. Wang, Z. Wei, K. Liu, and Y. Duan, Ultra-trace metallic element detection in liquid samples using laser induced breakdown spectroscopy based on matrix conversion and crosslinked PVA polymer membrane, J. Anal. At. Spectrom. 31(8), 1622 (2016)

91. S. L. Zhong, Y. Lu, W. J. Kong, K. Cheng, R. Zheng, Quantitative analysis of lead in aqueous solutions by ultrasonic nebulizer assisted laser induced breakdown spectroscopy, Front. Phys. 11(4), 114202 (2016)
92. L. Zheng, S. Niu, A. Q. Khan, S. Yuan, J. Yu, and H. Zeng, Comparative study of the matrix effect in $\mathrm{Cl}$ analysis with laser-induced breakdown spectroscopy in a pellet or in a dried solution layer on a metallic target, Spectrochim. Acta B At. Spectrosc. 118, 66 (2016)

93. S. Kashiwakura and K. Wagatsuma, Rapid sorting of stainless steels by open-air laser-induced breakdown spectroscopy with detecting chromium, nickel, and molybdenum, ISIJ Int. 55(11), 2391 (2015)

94. S. C. Yao, J. D. Lu, M. R. Dong, K. Chen, J. Y. Li, and J. Li, Extracting coal ash content from laser-induced breakdown spectroscopy (LIBS) spectra by multivariate analysis, Appl. Spectrosc. 65(10), 1197 (2011)

95. T. B. Yuan, Z. Wang, Z. Li, W. D. Ni, and J. M. Liu, A partial least squares and wavelet-transform hybrid model to analyze carbon content in coal using laser induced breakdown spectroscopy, Anal. Chim. Acta 807, 29 (2014)

96. Z. Wang, J. Feng, L. Z. Li, W. D. Ni, and Z. Li, A nonlinearized PLS model based on multivariate dominant factor for laser-induced breakdown spectroscopy measurements, J. Anal. At. Spectrom. 26(11), 2175 (2011)

97. X. Li, Z. Wang, S. L. Lui, Y. Fu, Z. Li, J. Liu, and W. Ni, A partial least squares based spectrum normalization method for uncertainty reduction for laserinduced breakdown spectroscopy measurements, Spectrochim. Acta B At. Spectrosc. 88, 180 (2013)

98. B. Zhang, L. X. Sun, H. B. Yu, Y. Xin, and Z. B. Cong, Wavelet denoising method for laser-induced breakdown spectroscopy, J. Anal. At. Spectrom. 28(12), 1884 (2013)

99. Z. Wang, L. Z. Li, L. West, Z. Li, and W. D. Ni, A spectrum standardization approach for laser-induced breakdown spectroscopy measurements, Spectrochim. Acta B At. Spectrosc. 68, 58 (2012)

100. L. X. Sun and H. B. Yu, Automatic estimation of varying continuum background emission in laser-induced breakdown spectroscopy, Spectrochim. Acta B At. Spectrosc. 64(3), 278 (2009)

101. B. Zhang, H. B. Yu, L. X. Sun, Y. Xin, and Z. B. Cong, A method for resolving overlapped peaks in laserinduced breakdown spectroscopy (LIBS), Appl. Spectrosc. 67(9), 1087 (2013)

102. L. X. Sun and H. B. Yu, Correction of self-absorption effect in calibration-free laser-induced breakdown spectroscopy by an internal reference method, Talanta 79(2), 388 (2009)

103. J. H. In, C. K. Kim, S. H. Lee, H. J. Lee, and S. Jeong, Improvement of selenium analysis during laser-induced breakdown spectroscopy measurement of $\mathrm{CuIn}_{1-x} \mathrm{Ga}_{x} \mathrm{Se}_{2}$ solar cell films by self-absorption corrected normalization, J. Anal. At. Spectrom. 28(8), 1327 (2013)

104. J. Feng, Z. Wang, L. West, Z. Li, and W. D. Ni, A PLS model based on dominant factor for coal analysis using laser-induced breakdown spectroscopy, Anal. Bioanal. Chem. 400(10), 3261 (2011) 
105. Y. Yu, Z. Q. Hao, C. M. Li, L. B. Guo, K. H. Li, Q. D. Zeng, X. Y. Li, Z. Ren, and X. Y. Zeng, Identification of plastics by laser-induced breakdown spectroscopy combined with support vector machine algorithm, Acta Phys. Sinica 62(21), 215201 (2013)
106. T. L. Zhang, L. Liang, K. Wang, H. S. Tang, X. F. Yang, Y. X. Duan, and H. Li, A novel approach for the quantitative analysis of multiple elements in steel based on laser-induced breakdown spectroscopy (LIBS) and random forest regression (RFR), J. Anal. At. Spectrom. 29(12), 2323 (2014) 